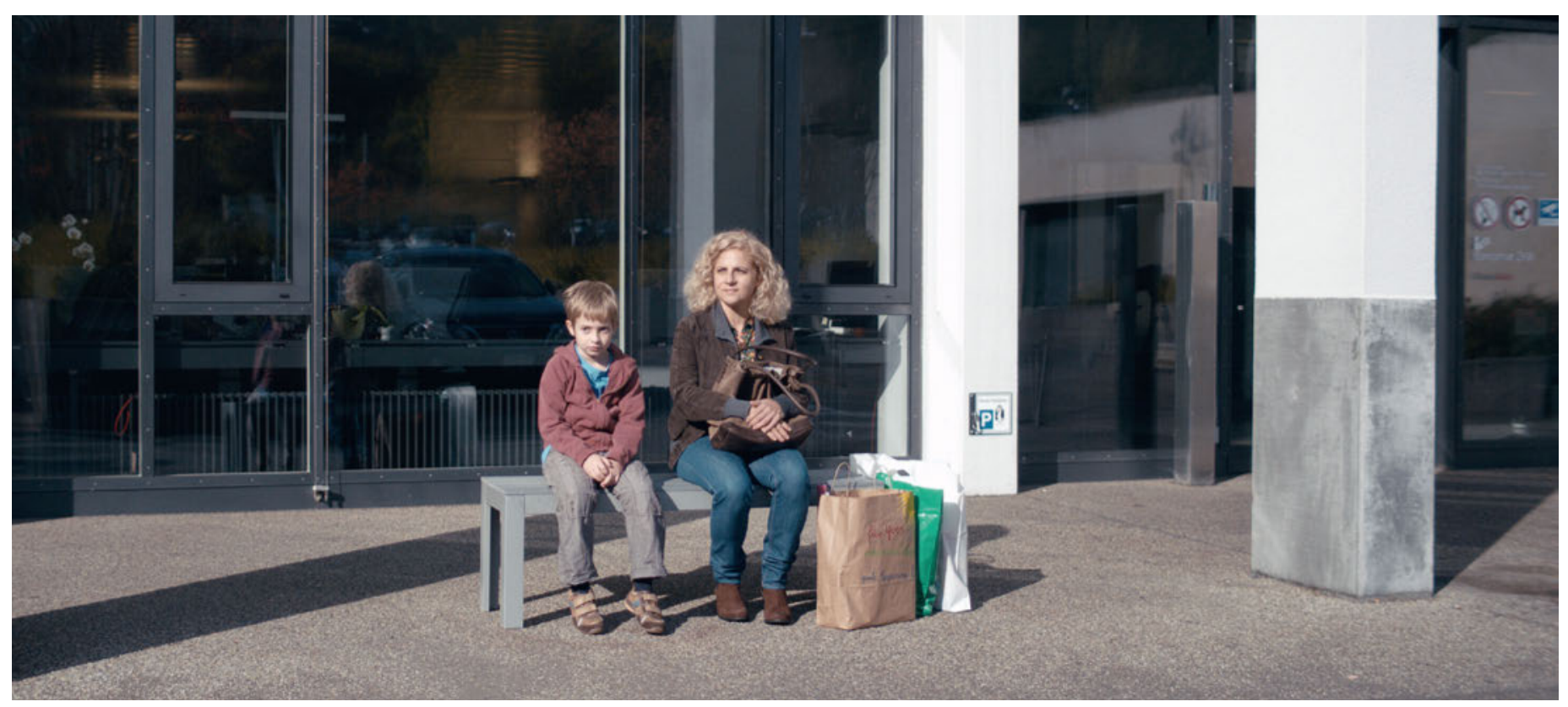

\title{
Finsteres Glück
}

\section{Eberhard Wolff}

PD Dr. rer. soc., Mitglied der Redaktion Medizingeschichte

In der Nacht nach der totalen Sonnenfinsternis des Jahres 1999 wird die Klinikpsychologin Eliane Hess ins Zürcher Waidspital an das Bett des achtjährigen Yves gerufen. Yves hat als Einziger seiner Familie einen schweren Autounfall überlebt. Der traumatisierte kleine Junge und die einfühlsame Therapeutin treten in eine Beziehung, die über die reine Behandlungsebene hinausreicht.

Der neue Film Finsteres Glück von Stefan Haupt basiert auf dem gleichnamigen Roman von Lukas Hartmann aus dem Jahr 2010. Darin geht es um eine tragische Familiengeschichte, den Kampf von Tante und Grossmutter um das Sorgerecht, die Nöte der behandelnden Psychologin, das Versagen der Behörden und die erstaunliche Kraft eines kleinen Jungen, sich getroffenen Entscheidungen zu widersetzen. Und nicht ganz nebenbei hat der kleine Yves am Ende eine grosse Wirkung auf die verkorkste Familiensituation im Hause Hess.

Vieles an diesem Film ist finster, oder besser: düster. Der Streit und die Gewalt in Yves' Familie. Die Beziehungserfahrungen, welche die Psychologin kühl und hart gemacht haben. Ihre eigene Familie mit zwei fast erwachsenen Töchtern ist am Limit. Yves' Trauertherapie wird zur Therapie ihrer eigenen Trauererfahrungen. Mit der Zeit werden alle an die Orte ihrer Verletzungen herangeführt.
Ein Film, so emotionsgeladen, dass er hier und da ins Klischee kippt. Die Psychologin wirkt beruflich und privat verzweifelt und hilflos, begegnet ihren Mitmenschen stets mit versteinerter Miene, zeigt kaum Spontaneität und scheint keinen Humor zu kennen.

Ein schöner, spannender Film. Aber kein Film, der sich differenziert mit persönlicher Betroffenheit in der Beziehung zu Patienten auseinandersetzt.

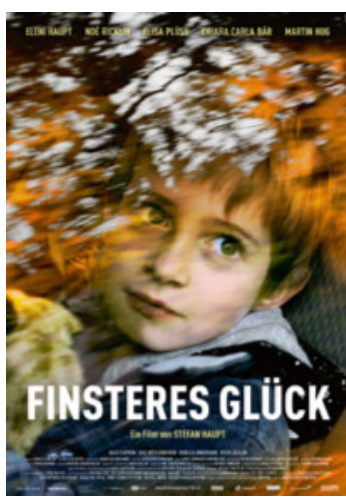

\section{Finsteres Glück}

Ein Film von

Stefan Haupt

Schweizer Dialekt. Mit Eleni Haupt, Noé Ricklin u.a.

Schweiz 2016,

114 Minuten.

Kinostart: 17. November. 